\title{
Creatine Kinase MM Measurement
}

National Cancer Institute

\section{Source}

National Cancer Institute. Creatine Kinase MM Measurement. NCI Thesaurus. Code C64494.

A quantitative measurement of the amount of homozygous M-type creatine kinase present in a sample. 